\title{
Multiplex real-time PCRs for detection of Salmonella, Listeria monocytogenes, and verotoxigenic Escherichia coli in carcasses of slaughtered animals
}

\author{
Edyta Denis, Katarzyna Bielińska, \\ Kinga Wieczorek, Jacek Osek \\ Department of Hygiene of Food of Animal Origin, \\ National Veterinary Research Institute, 24-100 Pulawy, Poland \\ josek@piwet.pulawy.pl
}

Received: May 9, 2016

Accepted: August 29, 2016

\begin{abstract}
Introduction: The study objective was to develop and evaluate a new TaqMan multiplex real-time PCR method for Salmonella, L. monocytogenes, and verotoxigenic Escherichia coli (VTEC) detection in slaughtered animal carcasses. Material and Methods: The procedure included an enrichment step, DNA extraction, and two multiplex real-time PCRs. The first PCR detected the invA and hly genes of Salmonella and L. monocytogenes respectively, the second the $v t x 1$, vtx 2 , and eae genes of VTEC. Results: The validation of this method resulted in $100 \%$ relative sensitivity, specificity, and accuracy as compared to the reference ISO methods. The limit of detection per swab sample was established at $1 \mathrm{cfu}$ for Salmonella and L. monocytogenes and 2 cfu for VTEC. The authors analysed 265 slaughterhouse-collected swabs from cattle, pig, and poultry carcasses. Among 125 from cattle, 51 were positive for VTEC, 29 for Salmonella, and 1 for L. monocytogenes. Among swabs from pig carcasses (n =95), three, two, and one sample were positive for these pathogens respectively. None of the microorganisms tested for was identified in 45 samples of poultry origin. Conclusion: The obtained results showed that the method developed can rapidly identify the main bacterial pathogens that may contaminate carcasses of food-producing animals.
\end{abstract}

Keywords: carcasses, foodborne pathogens, multiplex real-time PCRs, identification, food safety.

\section{Introduction}

Salmonella, Listeria monocytogenes, and verotoxigenic Escherichia coli (VTEC) have emerged as significant foodborne microorganisms and continue to be dangerous pathogens for human health $(4,22)$. In 2014 , a total of 96,831 confirmed cases of Salmonella, L. monocytogenes, and VTEC human infections were reported in the European Union, with incidences of $23.4,0.52$, and 1.56 cases per 100,000 population, respectively (4). Contamination of meat which occurs during slaughter and processing exposes consumers to a major risk of foodborne diseases (23). Thus, microbiological control at the slaughterhouse stage is highly important. Consequently, availability of rapid and specific methods for detection of foodborne microorganisms is essential. The ISO standards for Salmonella, L. monocytogenes, and VTEC O157 detection involve sample culture in pre-enrichment and selective media, followed by confirmation of bacterial isolates according to their morphological, biochemical, and immunological characteristics (10-13). These methods, although reliable and relatively inexpensive, are laborious and require several days before the analysis is completed (5). Furthermore, the obtained results often are not available before the food has been either released for trading or consumed, which may result in the spread of pathogens (15). To overcome these limitations of the ISO standards, several alternative detection methods have been developed, including those based on real-time PCR due to its sensitivity and specificity (18). Moreover, real-time PCR based on the use of specific primers and differently labelled probes allows for detection of more than one microorganism in a single reaction (30). Several studies have reported the application of 
multiplex real-time PCR for detection of Salmonella, L. monocytogenes, and E. coli O157, but to our knowledge, there have been no investigations including VTEC as a group of pathogenic E. coli $(6,7$, 16, 24, 27).

The aim of the present study was to develop and evaluate a new, effective TaqMan multiplex realtime PCR method for detection of Salmonella, L. monocytogenes, and VTEC in carcasses of slaughtered animals. The method consists of an initial enrichment step in non selective medium followed by DNA extraction and two real-time PCRs targeting the genes invA for Salmonella, hly for L. monocytogenes and stx1, stx2 and eae for VTEC An internal amplification control (IAC) was also included to monitor the possible presence of PCR inhibitors.

\section{Material and Methods}

Bacterial strains. Bacterial strains from the collection of the Department of Hygiene of Food of Animal Origin or obtained from the American Type Culture Collection were used (Tables 1 and 2). The bacteria were stored at $-80^{\circ} \mathrm{C}$, and for the study Salmonella and VTEC were grown on Lab-Agar (Biocorp, Poland), while L. monocytogenes was cultured on Tryptone Soya Yeast Extract Agar (Oxoid, $\mathrm{UK})$ at $37^{\circ} \mathrm{C}$ for $18-24 \mathrm{~h}$. All other bacteria were grown according to their individual requirements as described by the supplier.

DNA extraction. Bacterial DNA from the strains and swab samples was extracted with a Genomic Mini kit (A\&A Biotechnology, Poland) under the manufacturer's protocol. The original instruction was modified regarding the incubation time with lysostaphin (Sigma-Aldrich, USA) which was increased to $30 \mathrm{~min}$. In the initial step, $1 \mathrm{~mL}$ of the bacterial suspension was centrifuged at 13,000 $\mathrm{g}$ for 3 min and the cell pellet was used for DNA extraction.

Primers and probes for multiplex real-time PCRs. The following genes were selected for identification of the target microorganisms: invA (Salmonella), hly (L. monocytogenes), and stx1, stx2, and eae (VTEC). The primer and probe sequences (Table 3) were commercially designed by Blirt S.A. (Poland) using the NCBI Gene, CLC DNA Workbench 6, Beacon Designer Online Edition, NCBI Nucleotide Blast, and NCBI Primer Blast software applications. The oligonucleotides were provided by Metabion International AG (Germany).

Specificity of primers and probes. The reference bacterial strains (Tables 1 and 2) were used to test the specificity of the designed primers and probes in two real-time PCRs: one for Salmonella and L. monocytogenes and the other for VTEC. A total of 57 strains, including 41 target and 16 non-target bacteria, were used for validation of the real-time PCR for Salmonella and L. monocytogenes, and for VTEC amplifications of DNA from 53 strains (34 VTEC and 19 non-VTEC) were performed. In both reactions IAC was included to monitor a possible inhibition of PCR (Table 3).

Multiplex real-time PCRs. PCR amplification of the Salmonella- and L. monocytogenes-specific genes was performed in a final volume of $25 \mu \mathrm{L}$, containing $12.5 \mu \mathrm{L}$ of iQ Multiplex Powermix (Bio-Rad, USA), $300 \mathrm{nM}$ of each specific primer, $200 \mathrm{nM}$ of Ssinv and LMhly probes, $160 \mathrm{nM}$ and $80 \mathrm{nM}$ of IAC primers and probe respectively, $7 \times 10^{3}$ copies of IAC DNA, and $2.5 \mu \mathrm{L}$ of target DNA. In the PCR for VTEC the same primer and probe concentrations were used, with the IAC primers and probe at $240 \mathrm{nM}$ and $120 \mathrm{nM}$ respectively and $14 \times 10^{3}$ copies of IAC DNA. All amplifications were carried out in a CFX 96 Real-Time PCR Detection System (Bio-Rad) using the following thermal profile: $10 \mathrm{~min}$ at $95^{\circ} \mathrm{C}$, followed by 35 cycles of denaturation at $95^{\circ} \mathrm{C}$ for $15 \mathrm{~s}$ and $1 \mathrm{~min}$ at $60^{\circ} \mathrm{C}$ for the annealing/extension step.

Estimation of relative sensitivity, specificity, and accuracy. To estimate the relative sensitivity (SE), specificity (SP), and accuracy (AC) of the method, 10 blind and 20 spiked swab samples were analysed using multiplex real-time PCRs and the standard culture methods for Salmonella, L. monocytogenes, and E. coli O157 (10-13). The inoculation of sponges (Whirl-Pak Speci-Sponge bag, Nasco, USA) was done with low (10 cfu/swab, 10 samples) and high (100 cfu/swab, 10 samples) concentrations of the pathogens and in the presence of background microflora (E. coli, L. welshimerii, and $P$. aeruginosa, 50 cfu per sample of each). Then $100 \mathrm{~mL}$ of tryptone soya broth (TSB) (Oxoid) was added to each sample, which was subsequently stomached and incubated at $37^{\circ} \mathrm{C}$ for $24 \mathrm{~h}$. DNA was extracted and used in real-time PCRs. The parameters (SE, SP, AC) were calculated for each individual microorganism using the formulas specified in the ISO 16140:2003 standard (14).

Limit of detection. To determine the limit of detection (LOD), 30 sponges were inoculated with a low level of Salmonella, L. monocytogenes, and VTEC (10 samples with one cfu, 10 samples with two cfu, and 10 samples with three cfu) as well as spiked with background microflora (E. coli, L. welshimerii, and $P$. aeruginosa, $50 \mathrm{cfu}$ per sample of each). Then $100 \mathrm{~mL}$ of TSB was added, and the samples were homogenised, and incubated at $37^{\circ} \mathrm{C}$ for $24 \mathrm{~h}$. After DNA extraction, two multiplex real-time PCRs for Salmonella, L. monocytogenes, and VTEC were performed. The limit of detection was determined for each individual microorganism and it was assumed as the level at which $70 \%$ of positive results were achieved.

Analysis of natural samples. Slaughterhouse visits collected 265 swabs from cattle $(n=125)$, pig $(n=95)$ and poultry $(n=45)$ carcasses and these were examined. Cattle and pig carcasses were swabbed with four sterile sponges in the brisket area $\left(400 \mathrm{~cm}^{2}\right)$ after 
evisceration of the animals. In the case of poultry carcasses, the skin surface was wiped with sterile swabs directly before chilling. All samples were transported to the laboratory in an ice-pack container and analysed within $24 \mathrm{~h}$. The cattle and pig sponges received $160 \mathrm{~mL}$ of TBS and $10 \mathrm{~mL}$ was added to the poultry samples, all then being stomached and incubated at $37^{\circ} \mathrm{C}$ for $24 \mathrm{~h}$. DNA was extracted and used in real-time PCRs as described above.

Table 1. Bacterial strains used in development and validation of real-time PCR for Salmonella and L. monocytogenes

\begin{tabular}{|c|c|c|c|c|c|}
\hline \multirow{2}{*}{ Strain } & \multicolumn{2}{|c|}{ Presence of genes } & \multirow[t]{2}{*}{ Strain } & \multicolumn{2}{|c|}{ Presence of genes } \\
\hline & invA & hly & & $\operatorname{inv} A$ & hly \\
\hline Salmonella Anatum ATCC 9270 & + & & L. monocytogenes 3c (id. 04CEB717LM) & - & + \\
\hline Salmonella Arizonae ATCC 13314 & + & - & Listeria ivanovii ATCC 19119 & - & - \\
\hline Salmonella Enteritidis ATCC 13076 & + & - & Listeria innocua ATCC 33090 & - & - \\
\hline Salmonella Paratyphi A ATCC 9150 & + & - & Listeria seeligeri ATCC 35967 & - & - \\
\hline Salmonella Typhimurium ATCC 14028 & + & - & Listeria welshimeri ATCC 35897 & - & - \\
\hline Salmonella Schleissheim (id. 1, 2, 3, 4, 5, 6) & + & - & Campylobacter coli ATCC 43478 & - & - \\
\hline Salmonella Typhimurium (id. 7) & + & - & Campylobacter jejuni ATCC 33560 & - & - \\
\hline Salmonella Enteritidis (id. 8, 9, 12, 13, 14, 15) & + & - & Clostridium perfringens ATCC 13124 & - & - \\
\hline Salmonella Dublin (id. 10, 11, 16, 17) & + & - & Escherichia coli ATCC 43888 & - & - \\
\hline Salmonella London (id. 18) & + & - & Escherichia coli ATCC 8739 & - & - \\
\hline Listeria monocytogenes ATCC 19118 & - & + & Escherichia coli ATCC 43889 & - & - \\
\hline L. monocytogenes $1 / 2 \mathrm{a}$ (id. $2,3,1 \mathrm{M}, 05 \mathrm{CEB} 424 \mathrm{LM})$ & - & + & Escherichia coli ATCC 25922 & - & - \\
\hline $\begin{array}{l}\text { L. monocytogenes } 1 / 2 \mathrm{~b} \text { (id. } 9,34 \mathrm{M}, 42 \mathrm{M} \text {, } \\
\text { 06CEB406LM) }\end{array}$ & - & + & Kocuria rhizophila ATCC 9341 & - & - \\
\hline L. monocytogenes $1 / 2 \mathrm{c}$ (id. 1, 7M, 06CEB405LM) & - & + & Pseudomonas aeruginosa ATCC 27853 & - & - \\
\hline L. monocytogenes $4 \mathrm{~b}$ (id. 22, 76M, 06CEB422LM) & - & + & Rhodococcus equi ATCC 6939 & - & - \\
\hline L. monocytogenes 3a (id. 06CEB36LM) & - & + & Staphylococcus aureus ATCC 25923 & - & - \\
\hline L. monocytogenes 3b (id. 06CEB712LM) & - & + & Vibrio parahaemolyticus ATCC 17802 & - & - \\
\hline
\end{tabular}

Table 2. Bacterial strains used in development and validation of real-time PCR for VTEC

\begin{tabular}{|c|c|c|c|c|c|c|c|}
\hline \multirow{2}{*}{ Strain } & \multicolumn{3}{|c|}{ Presence of genes } & \multirow{2}{*}{ Strain } & \multicolumn{3}{|c|}{ Presence of genes } \\
\hline & stx 1 & stx 2 & eae & & stx 1 & stx2 & eae \\
\hline VTEC O26 (id. G08) & - & - & + & VTEC O146 (id. 560) & + & + & - \\
\hline VTEC O91 (id. F08) & + & - & - & VTEC O157:H7 ATCC 43888 & - & + & - \\
\hline VTEC O103 (id. E08, 697, 3160) & + & - & + & VTEC O157:H7 ATCC 43889 & - & + & + \\
\hline VTEC O111 (id. C08) & + & + & + & Escherichia coli ATCC 8739 & - & - & - \\
\hline VTEC O121 (id. B08, 5833, 9900) & - & + & + & Escherichia coli ATCC 25922 & - & - & - \\
\hline VTEC O145 (id. A08) & + & - & + & Campylobacter coli ATCC 43478 & - & - & - \\
\hline VTEC O157 (id. D08, 251, 1098, 5346) & - & + & + & Campylobacter jejuni ATCC 33560 & - & - & - \\
\hline VTEC O84:H28 (id. 13) & + & - & + & Clostridium perfringens ATCC 13124 & - & - & - \\
\hline VTEC O2:H32 (id. 17) & - & + & - & Listeria innocua ATCC 33090 & - & - & - \\
\hline VTEC O153:H2 (id. 21) & - & + & - & Listeria ivanovii ATCC 19119 & - & - & - \\
\hline VTEC O21:H25 (id. 23, 27) & - & + & - & Listeria seeligeri ATCC 35967 & - & - & - \\
\hline VTEC O153:H25 (id. 26) & - & + & - & Listeria welshimeri ATCC 35897 & - & - & - \\
\hline VTEC O117:H4 (id. 42) & - & + & - & Kocuria rhizophila ATCC 9341 & - & - & - \\
\hline VTEC O139:H19 (id. 44) & - & + & - & Pseudomonas aeruginosa ATCC 27853 & - & - & - \\
\hline VTEC O174:H2 (id. 45, 46) & - & + & - & Rhodococcus equi АTCC 6939 & - & - & - \\
\hline VTEC O185:H7 (id. 47) & - & + & - & Staphylococcus aureus ATCC 25923 & - & - & - \\
\hline VTEC O2:H6 (id. 50) & - & + & - & Vibrio parahaemolyticus ATCC 17802 & - & - & - \\
\hline VTEC O113:H21 (id. 57) & - & + & - & Salmonella Anatum ATCC 9270 & - & - & - \\
\hline VTEC O8:H16 (id. 60) & - & + & - & Salmonella Arizonae ATCC 13314 & - & - & - \\
\hline VTEC O152:H8 (id. 61) & + & - & - & Salmonella Enteritidis ATCC 13076 & - & - & - \\
\hline VTEC O26 (id. 9440) & - & + & + & Salmonella Paratyphi A ATCC 9150 & - & - & - \\
\hline VTEC O111 (id. 6030) & + & - & + & Salmonella Typhimurium ATCC 14028 & - & - & - \\
\hline
\end{tabular}


Table 3. Primers, probes, and IAC for Salmonella, L. monocytogenes, and VTEC used for multiplex real-time PCRs

\begin{tabular}{|c|c|c|c|}
\hline Microorganism & Target gene & Primers and probes & Sequence $\left(5^{\prime} \rightarrow 3^{\prime}\right)$ \\
\hline \multirow{3}{*}{ Salmonella } & \multirow{3}{*}{$\operatorname{inv} A$} & Ssinv-probe & 6-FAM-CCTGAATTACTGATTCTGGTACTAATGGTGATG-BHQ1 \\
\hline & & SS-F & GCTTTCTCTACTTAACAGTGCTC \\
\hline & & SS-R & CAGTGCGATCAGGAAATCAAC \\
\hline \multirow{3}{*}{ L. monocytogenes } & \multirow{3}{*}{ hly } & LMhly-probe & HEX-CACTCTGGAGGATACGTTGCTCAATTCAAC-BHQ1 \\
\hline & & $\mathrm{LM}-\mathrm{F}$ & CAACTCAGAATATATTGAAACAACTTC \\
\hline & & LM-R & ACAATTTCGTTACCTTCAGGATC \\
\hline \multirow{9}{*}{ VTEC } & \multirow{3}{*}{ stx 1} & stx1-probe & 6-FAM-CGCATAGTGGAACCTCACTGACGCA-BHQ1 \\
\hline & & stx $1-\mathrm{F}$ & CATTCGTTGACTACTTCTTATCTGG \\
\hline & & stx $1-\mathrm{R}$ & ACGTAAAGCTTCAGCTGTCAC \\
\hline & \multirow{3}{*}{ stx 2} & stx2-probe & HEX-ACCGTTACTGCAAAGTGCTCAGTTGACAG-BHQ1 \\
\hline & & stx2-F & GACACATTTACAGTGAAGGTTGAC \\
\hline & & stx2-R & CAGGTACTGGATTTGATTGTGAC \\
\hline & \multirow{3}{*}{ eae } & eae-probe & TXR-AGTCAGTTTATTTGTATGACCAGCGACACC-BHQ2 \\
\hline & & eae-F & GTTCGGCACCTCTTGTTGC \\
\hline & & eae- $R$ & CCTTGTCATCGGTCATGTTGC \\
\hline \multirow{3}{*}{ IAC } & \multirow{3}{*}{-} & IAC-probe & Cy5-CATCATGCGATGTCTGTTGCTTCTAATCCA-BHQ3 \\
\hline & & IAC-F & GGAGACCACAACGGTTTCC \\
\hline & & IAC-R & TAAGAAATCAGATGGATTTGGACC \\
\hline
\end{tabular}

\section{Results}

All Salmonella $(\mathrm{n}=23)$ reference strains were positive for the invA gene, as were those of L. monocytogenes $(\mathrm{n}=18)$ for hly, and of VTEC $(\mathrm{n}=34)$ for $s t x 1$, stx 2 , and eae, showing the specificity of the primers and probes used. The obtained threshold cycle $(\mathrm{Ct})$ values in multiplex reactions ranged from 15.5 to 20.1 for Salmonella, from 19.5 to 22.5 for L. monocytogenes, and from 16.4 to 26.0 for VTEC. All non-target strains used were negative for all these gene markers. The validation of the developed method involved determination of the SE, SP, and AC. The parameters were calculated for each individual pathogen based on the results of the analysis of 10 blind and 20 artificially inoculated swab samples with Salmonella, L. monocytogenes, and E. coli $\mathrm{O} 157$ by multiplex real-time PCRs and reference methods. The obtained PCR results showed SE, SP, and AC at 100\% levels compared to the ISO standards. The LOD was established at one cfu per swab for Salmonella $(90 \%$ positive results with $\mathrm{Ct}$ range from 23.75 to 27.37 ) and L. monocytogenes (70\% positive results with $\mathrm{Ct}$ from 27.91 to 31.10$)$, and two cfu for VTEC (80\% positive results, $\mathrm{Ct}$ from 20.72 to 23.35). The method developed was used to analyse 265 swabs collected at slaughterhouses from cattle, pig, and poultry carcasses. Among 125 samples from cattle, 51 were positive for VTEC (Ct 20.06-32.17), 29 for Salmonella (Ct 22.2832.03), and 1 for L. monocytogenes (Ct 29.89). Three (Ct 30.40-30.94), two (Ct 31.07-32.07), and one (Ct 29.46) swab from pigs $(\mathrm{n}=95)$ were also positive for these pathogens respectively. None of the microorganisms tested for was detected in 45 samples from poultry carcasses.

\section{Discussion}

Salmonella, L. monocytogenes, and VTEC are still recognised as the most dangerous foodborne bacterial pathogens (4). In the present study, multiplex realtime PCRs for simultaneous detection of these microorganisms were developed and evaluated. The method involved an initial enrichment step in TSB followed by DNA extraction, and two TaqMan based real-time PCRs for the invA, hly, stx1, stx2, and eae target genes. In the first stage of the study the nonselective medium was used to allow simultaneous growth of the pathogens and thereby to improve the efficiency of the detection process. Such media as TSB, buffered peptone water (BWP), No. 17 medium, and universal pre-enrichment broth (UPB) were also used in multiplex PCR based methods by other authors (1, 3, 8, 16). However, some studies reported that nonselective media may cause false negative results, especially by interference with complex background flora present in analysed samples (19). Therefore, the use of selective enrichment broth for simultaneous cultivation of multiple pathogens was also described (28), but it should be underlined that such media may inhibit or delay the growth of target microorganisms (31). Moreover, in the present study, one enrichment step was used for Gram-positive and Gram-negative microorganisms, whereas some authors have reported that detection of L. monocytogenes with PCR method is less sensitive and have recommended two enrichment steps (21). The obtained results demonstrated that the use of TSB was suitable for simultaneous growth of Salmonella, VTEC, and L. monocytogenes. The LOD was established at one cfu per swab for Salmonella and L. monocytogenes and two cfu for VTEC. Background 
microflora present in the analysed samples ( $E$. coli, L. welshimerii, and $P$. aeruginosa) did not significantly interfere with the LOD, even when the samples were inoculated with the target pathogens at low levels. It was reported that the DNA isolation procedure had a strong effect on the efficiency of the detection process in real-time multiplex PCR (16). It is very important that the protocol used successfully eliminate inhibitors that can affect the PCR results by lowering or completely preventing the amplification (20). The effectiveness of this process could be verified by the $\mathrm{Ct}$ values obtained for the IAC. In the current study, no remarkable alterations were detected when natural or contaminated samples were analysed.

The most important stage of the present study was to design the primers and probes used in two real-time PCRs, which determine the reliability of the developed method. This step is especially important during the development of multiplex assays, where the presence of more than one primer pair and probe increases the probability of nonspecific interactions (26). The pathogen-specific oligonucleotides were selected to target the genes invA for Salmonella, hly for L. monocytogenes, and stx1, stx2, and eae for VTEC, which were previously described as optimal markers for these bacteria. The invA marker contains a highly conserved sequence unique for Salmonella DNA and its amplification is considered the international gold standard for detection of this pathogen (9). Several virulence-associated markers have been proposed for L. monocytogenes identification, but the hly gene, which encodes listeriolysin $\mathrm{O}$, is one of the most frequently used (17, 29). Regarding VTEC, the virulence markers stx 1 , stx2, and eae targeted in the present study encode Shiga toxins and adhesion protein intimin respectively (2). VTEC detection based on these genes has previously been documented well (25). The specificity of primers and probes used in the present study was confirmed with 110 bacterial strains including 75 target and 35 non-target strains. Moreover the results of validation of the method developed showed a $100 \% \mathrm{SE}, \mathrm{SP}$, and AC as compared to the reference methods. The usefulness of the protocol developed was determined with natural samples from 265 slaughterhouse carcasses. Among them 54 were positive for VTEC, 31 for Salmonella, and 2 for L. monocytogenes. IAC gave positive results for all analysed samples, proving that there was no matrix inhibition.

In conclusion, a new multiplex real-time PCR method was developed for detection of Salmonella, L. monocytogenes, and VTEC in carcasses of slaughtered animals. The assay showed a high SE, SP, and AC, and achieved a low LOD. The method may be a valuable alternative to the ISO standard investigations and allows rapid and specific detection of foodborne pathogens in animal carcasses before their commercial distribution. In the future, the evaluation of this assay for other food matrices may also extend its application in food safety analyses.

Conflict of Interests Statement: The authors declare that there is no conflict of interests regarding the publication of this article.

Financial Disclosure Statement: This work was supported by S/151 "Development and validation of real-time PCR method for identifications of selected pathogenic microorganisms in carcasses of slaughtered animals" and S/223 "Application of the real-time PCR method for identification of selected pathogenic microorganisms in carcasses of slaughtered animals" conducted within the statutory activity of the National Veterinary Research Institute in Pulawy, Poland.

Animal Rights Statement: None required.

\section{References}

1. Alarcón B., García-Cañas V., Cifuentes A., González R., Aznar R.: Simultaneous and sensitive detection of three foodborne pathogens by multiplex PCR, capillary gel electrophoresis, and laser-induced fluorescence. J Agric Food Chem 2004, 52, 7180-7186.

2. Beutin L., Miko A., Krause G., Pries K., Haby S., Steege K., Albrecht N.: Identification of human-pathogenic strains of Shiga toxin producing Escherichia coli from food by a combination of serotyping and molecular typing of Shiga toxin genes. Appl Environ Microbiol 2007, 73, 4769-4775.

3. Bhagwat A.A.: Simultaneous detection of Escherichia coli O157:H7, Listeria monocytogenes and Salmonella strains by real-time PCR. Int J Food Microbiol 2003, 84, 217-224.

4. EFSA (European Food Safety Authority) and ECDC (European Centre for Disease Prevention and Control): The European Union summary report on trends and sources of zoonoses, zoonotic agents and food-borne outbreaks in 2014. EFSA J 2015, 13, 4329, 191 pp.doi:10.2903/j.efsa.2015.4329

5. Garrido A., Chapela M.J., Román B., Fajardo P., Vieites J.M., Gabado A.G.: Development of a multiplex real-time PCR method for simultaneous detection of Salmonella enterica, Shigella flexneri and Listeria monocytogenes in processed food samples. Eur Food Res Technol 2012, 234, 571-580.

6. Garrido A., Chapela M.J., Román B., Fajardo P., Vieites J.M.: A new multiplex real-time PCR developed method for Salmonella spp. and Listeria monocytogenes detection in food and environmental samples. Food Control 2013, 30, 76-85.

7. Garrido A., Chapela M.J., Román B., Fajardo P., Vieites J.M., Gabado A.G.: In-house validation of multiplex real-time PCR method for simultaneous detection of Salmonella spp., Escherichia coli $\mathrm{O} 157$ and Listeria monocytogenes. Int J Food Microbiol 2013, 164, 92-98.

8. Gehring A.G., Albin D.M., Bhunia A.K., Kim H., Reed S.A., Tu S.-I.: Mixed culture enrichment of Escherichia coli O157:H7, Listeria monocytogenes, Salmonella enterica, and Yersinia enterocolitica. Food Control 2012, 26, 269-273.

9. Hohmann E.L.: Nontyphoidal salmonellosis. Clin Infect Dis 2001, 32, 263-269.

10. ISO: International Organization for Standardization, EN ISO 11290-1:1996 - Microbiology of food and animal feeding stuffs - Horizontal method for the detection and enumeration of Listeria monocytogenes - Part 1: Detection method. Geneva, Switzerland.

11. ISO: International Organization for Standardization, EN ISO 16654:2001 - Microbiology of food and animal feeding stuffs - 
Horizontal method for the detection of Escherichia coli O157. Geneva, Switzerland.

12. ISO: International Organization for Standardization, EN ISO 6579:2002 - Microbiology of food and animal feeding stuffs Horizontal method for the detection of Salmonella spp. Geneva, Switzerland.

13. ISO: International Organization for Standardization, EN ISO 11290-1/A1:2005 - Microbiology of food and animal feeding stuffs - Horizontal method for the detection and enumeration of Listeria monocytogenes - Part 1: Detection method Amendment 1: modification of the isolation media, of the haemolysis test and inclusion of precision date. Geneva, Switzerland.

14. ISO: International Organization for Standardization, EN ISO 16140:2003 - Microbiology of food and animal feeding stuffs Protocol for the validation of alternative methods. Geneva, Switzerland.

15. Kagkli D.M., Weber T.P., Van den Bulcke M., Folloni S., Tozzoli R., Morabito S., Ermolli M., Gribaldo L., Van den Eede G.: Application of the modular approach to an in-house validation study of real-time PCR methods for the detection and serogroup determination of Verocytotoxigenic Escherichia coli. Appl Environ Microbiol 2011, 77, 6954-6963.

16. Kawasaki S., Fratamico P.M., Horikoshi N., Okada Y., Takeshita K., Sameshima T., Kawamoto S.: Multiplex real-time polymerase chain reaction assay for simultaneous detection and quantification of Salmonella species, Listeria monocytogenes, and Escherichia coli $\mathrm{O} 157: \mathrm{H7}$ in ground pork samples. Foodborne Pathog Dis 2010, 7, 549-554.

17. Kędrak-Jabłońska A., Budniak S., Szczawińska A., Reksa M., Krupa M., Szulowski K.: Application of SYBR Green I and TaqMan probe-based real-time PCRs for identification of Listeria spp. and Listeria monocytogenes. Bull Vet Inst Pulawy 2015, 59, 489-494.

18. Law J.W., Nurul-Syakima A.M., Chan K.G., Lee L.H.: Rapid methods for the detection of foodborne bacterial pathogens: principles, applications, advantages and limitations. Front Microbiol 2015, 5, 770.

19. Lindner J.D.D., Santarelli M., Yamaguishi C.T., Soccol C.R., Neviani E.: Recovery and identification of bovine colostrum microflora using traditional and molecular approaches. Food Technol Biotechnol 2011, 49, 364-368.
20. Lund M., Madsen M.: Strategies for the inclusion of an internal amplification control in conventional and real time PCR detection of Campylobacter spp. in chicken fecal samples. Mol Cell Probes 2006, 20, 92-99.

21. Navas J., Ortiz S., Lopez P., Jantzen M.M., Lopez V., MartinezSuarez J.V.: Evaluation of effects of primary and secondary enrichment for the detection of Listeria monocytogenes by realtime PCR in retail ground chicken meat. Foodborne Pathog Dis 2006, 3, 347-354.

22. Newell D.G., Koopmans M., Verhoef L., Duizer E., AidaraKane A., Sprong H., Opsteegh M., Langelaar M., Threfall J., Scheutz F., van der Giessen J., Kruse H.: Food-borne diseases The challenges of 20 years ago still persist while new ones continue to emerge. Int J Food Microbiol 2010, 139, 3-15.

23. Norrung B., Buncic S.: Microbial safety of meat in the European Union. Meat Sci 2008, 78, 14-24.

24. Omiccioli E., Amagliani G., Brandi G., Magnani M.: A new platform for real-time PCR detection of Salmonella spp., Listeria monocytogenes and Escherichia coli $\mathrm{O} 157$ in milk. Food Microbiol 2009, 26, 615-622.

25. Padola N.L.: Advances in detection methods for Shiga toxinproducing Escherichia coli (STEC). Front Microbiol 2014, 5, 277.

26. Rodriguez A., Rodriguez M., Cordoba J.J., Andrade M.J.: Design of primers and probes for quantitative real-time PCR method. Methods Mol Biol 2015, 1275, 31-56.

27. Suo B., He Y., Tu SI., Shi X.: A multiplex real-time polymerase chain reaction for simultaneous detection of Salmonella spp., Escherichia coli $\mathrm{O} 157$, and Listeria monocytogenes in meat products. Foodborne Pathog Dis 2010, 7, 619-628.

28. Suo B., Wang Y.: Evaluation of a multiplex selective enrichment broth SEL for simultaneous detection of injured Salmonella, Escherichia coli $\mathrm{O} 157: \mathrm{H} 7$ and Listeria monocytogenes. Braz J Microbiol 2013, 44, 737-742.

29. Välimaa A.L., Tilsala-Timisjärvi A., Virtanen E.: Rapid detection and identification methods for Listeria monocytogenes in the food chain - A review. Food Control 2015, 55, 103-114.

30. Wittwer C.T., Herrmann M.G., Gundry C.N., Elenitoba-Johnson K.S.J.: Real-time multiplex PCR assays. Methods 2001, 25, 430-442.

31. Wu V.C.: A review of microbial injury and recovery methods in food. Food Microbiol 2008, 25, 735-744. 